\title{
Methods and Countermeasures of Controlling Drilling Cost under New Normal
}

\author{
Haixu Qu1, He Huang2, Haiqing Cui'1, Jingjie Liu ${ }^{3}$, Liang Zhao ${ }^{4}$ \\ ${ }^{1}$ School of Petroleum Engineering, Northeast Petroleum University, Daqing, China \\ ${ }^{2}$ Economic Evaluation Center for Exploration and Development of Liaohe Oilfield Company, Panjin, China \\ ${ }^{3}$ Special Oil Company of Liaohe Oilfield, Panjin, China \\ ${ }^{4}$ Research Institute of Petroleum Exploration and Development, Beijing, China \\ Email: haixu0825@163.com
}

Received 30 November 2015; accepted 21 December 2015; published 24 December 2015

Copyright (C) 2015 by authors and Scientific Research Publishing Inc.

This work is licensed under the Creative Commons Attribution International License (CC BY). http://creativecommons.org/licenses/by/4.0/

(c) (i) Open Access

\begin{abstract}
The oil price drops in the international crude oil market and the benefit of upstream operations reduces which has been the new normal of oil companies so far. The upstream operations production and management of oil companies face numerous problems and challenges. One of the most significant aspects is to control and optimize investment. Drilling investment is an important component of development investment in drilling oil and gas wells. This paper proposes ways and countermeasures of controlling drilling cost from 3 aspects which are technology innovation, management innovation and system innovation on basis of studying drilling cost structure and influence factors analysis. The results have some guidance and exemplary significance to show how to improve production and management effect respectively on upstream operations of oil companies under new normal.
\end{abstract}

\section{Keywords}

New Normal, Drilling Cost, Upstream Operations, Investment, Innovation

\section{Introduction}

The onshore oilfield development in our country has entered a new stage. The obvious characteristics are the coexisting of high water cut, high recovery percentage, low grade of new reserves and low production of single well. In order to guarantee state oil and gas supply and to increase oil production fast, the new production capacity increases leading to the continuous increase of the capacity building workload though the exploration and development targets are more and more complex. The overall investment of upstream operations surges with 
production decline of single well and drilling workload increase. Taking some Chinese oil companies for example, the total oil and gas exploration and development investment and cost in 2015 increase 4 times than 2000. The oil and gas development benefit drops fast and ROIC decreases continually) because of the oil and gas development cost and depreciation and operation cost which increase obviously.

In recent years, the idea of focusing on benefit has enhanced further under the guidance of development policy which is quality, benefit and sustainability [1]. Especially under the current low oil price environment, to control investment, to cut down costs and to improve effects are the themes of current management work. The drilling investment accounts for $50 \%$ in oil and gas development investment structure. Taking some Chinese oil companies for example, the drilling engineering and surface engineering investment ratio has increased from 59\% in 2000 to $72 \%$ in 2015 wherein the surface engineering investment is still about $20 \%$ in the oil and gas development structure. The increase of drilling engineering investment causes the increase of the total exploration and development investments with time going by, so reducing the drilling cost is an effective way to control investment and cut down cost now. It is significant to improve the total benefit of upstream operations [2]. This paper proposes ways and countermeasures of controlling drilling cost from 3 aspects which are technology innovation, management innovation and system innovation on basis of studying drilling cost structure and influence factor analysis. The results demonstrate guidance and exemplary significance to show how to improve production and management benefits for upstream operations of oil companies under new situation.

\section{Questions}

\subsection{Composition of Drilling Cost}

The common drilling cost includes the investment of all the projects from drilling preparation to the end of well testing and installment of production tree at last. These projects include six major projects, such as drilling preparation, well drilling, cementing, logging, well logging interpretation and well testing. There are more than forty kinds of cost in different production stages of these six major projects (Figure 1).

Take the drilling cost of some oilfield in China for example. It is visible through the data analysis that the direct factors affecting the drilling cost include well type, casing program, lithology of reservoir, drilling footage, drilling cycle, drilling materials selection(casing, cement, drill bit, drilling fluid, etc.), drilling complexity and accident, etc. (Figure 2)

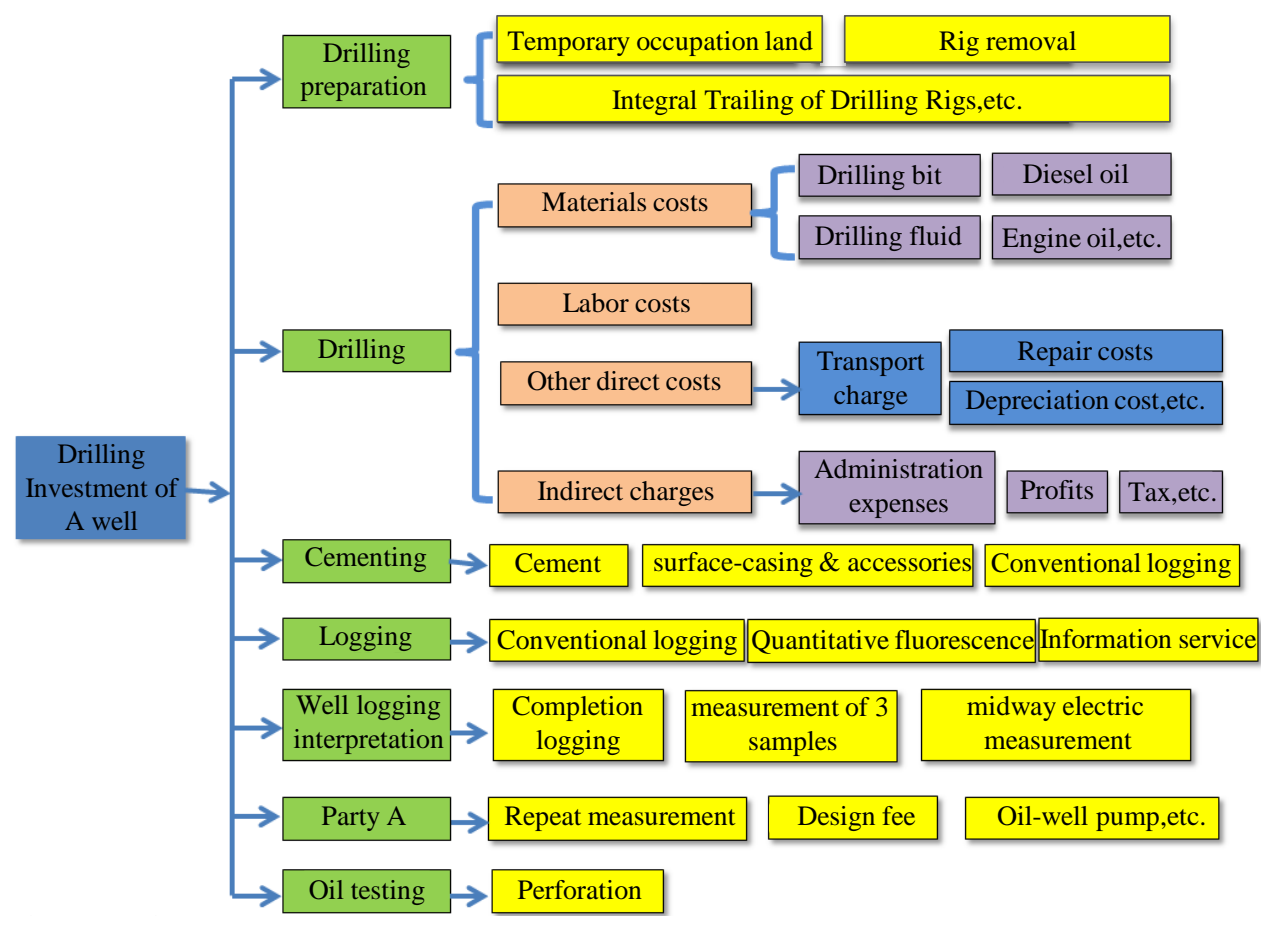

Figure 1. Single well investment structure. 


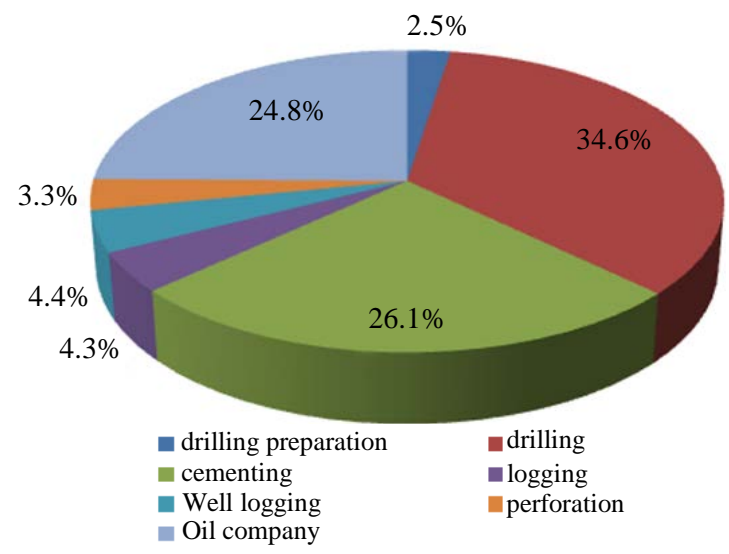

Figure 2. Drilling cost of single well.

\subsection{Influence Factors of Drilling Cost}

Because of the specificity of drilling engineering, different factors impact the drilling cost during different stages. According to the data analysis, major aspects impacting drilling cost can be summarized as the followings:

1) The more drilling footage, the higher drilling cost, and vice versa.

2) The longer drilling cycle, the higher drilling cost, and vice versa.

3) The tighter formation, the longer drilling cycle, and the higher drilling cost.

4) Well type includes side-track wells, vertical wells, horizontal wells, and different well types correspond to different drilling costs.

5) Drilling accidents and failures increase the drilling cost.

6) Surface casing and production casing are related to the length of cementing well section, and the longer cementing well section, the higher drilling costs.

7) Different drilling bits have different prices and have significant impact on drilling cycles and efficiency.

8) Different components of drilling fluids results in different costs, water-base drilling fluid has lower price compared to oil-base drilling fluid.

9) Different well sketches have different costs due to different casing locations and wellhead equipment.

Based on the above factors (Figure 3), the drilling footage and drilling cycle are the main components of the drilling costs [3]. In management accounting, fixed costs are defined as expenses that do not change as a function of the activity of a business, within the relevant period. For example, a retailer must pay rent and utility bills irrespective of sales. Variable costs are costs that change in proportion to the good or service that a business produces. The variable costs are volume-related and are relatively stable in the evaluation period. The drilling cost can be also divided into fixed and variable costs. The fees that are not affected by the drilling footage and drilling cycle are called fixed costs. The expenses that are influenced by the drilling footage and drilling cycle are called variable costs.

From the conventional drilling cost (based on China single well drilling cost), we get the single well drilling cost structure (Figure 2) and the ratio of fixed and variable costs in cost structure of single well drilling (Table 1).

Through the above analysis, it can be seen that $100 \%$ of pre-drilling engineering cost is the fixed cost; the core-taking bit, fee of drilling tool transferring and repairing cost of well controlling unit in drilling engineering are fixed costs, and $98.3 \%$ of the other costs are variable costs; cementing engineering cost involving the casing, lightening admixture, expansive agent and so on are the variable costs accounting for $86.4 \%$; in the mud logging engineering, except for the data is fixed cost, the rest are the variable cost accounting for $98.5 \%$; both logging interpretation and perforation are variable costs. Variable costs account for high proportion of the drilling cost. Therefore, on the premise of ensuring safety in oilfield production, it can realize the purpose of cost-saving and profit-increasing to control the variable cost in the drilling cost.

\section{Methods}

\subsection{The Technological Innovation Is the Basis of Controlling Drilling Cost}

The scientific and technological advancement is the driving power of enterprise development, and the exploitation 


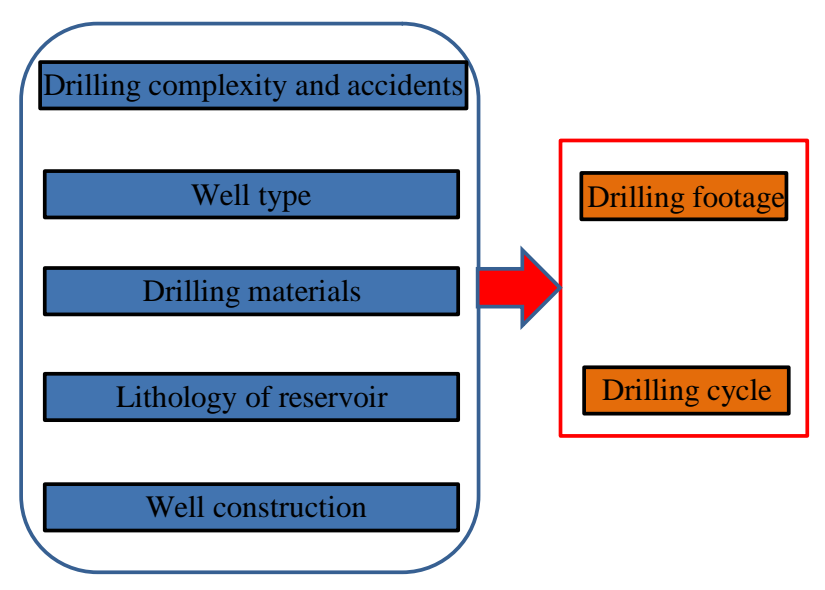

Figure 3. Fixed and variable impact factors of drilling cost.

Table 1. Fixed and variable proportion of single well drilling cost.

\begin{tabular}{ccc}
\hline Cost components & Fixed proportion (\%) & Variable proportion (\%) \\
\hline Drilling preparation & 100 & 0 \\
Drilling & 1.7 & 98.3 \\
Cementing & 13.6 & 86.4 \\
Subtotal & 7.5 & 92.5 \\
Logging & 1.5 & 98.5 \\
Well logging & 0 & 100 \\
Perforation & 0 & 100 \\
Party A & 100 & 0 \\
Mean value & 29.5 & 70.5 \\
\hline
\end{tabular}

of technological potential is one of the effective ways on cost-saving and profit-increasing across all industries. Also the technological innovation is the only way for well-drilling development [4]. In the course of technological innovation, investment-increasing will contradict with nature of cost-saving and profit-increasing. However, in fact, as long as investment of technological innovation is reasonably planned, the cost will possibly rise up in short term to some extent. Once the innovation outcomes are applied effectively and practically, benefit created by the innovation outcomes is much considerable in long-term production. For example, the slim hole drilling technology was successively applied in Qinghai oilfield, the drilling period was shorten by 2 days compared to other drilling technologies and drilling cost of single well was saved 1million RMB. In addition, as advanced drilling technologies such as horizontal well, MBL, infill well developed, the larger the contact area between wellbore and reservoir, the more well-controlled reserve, the smaller well site area, which can effectively increase oil and gas recovery and reduce environmental impact. As scientific and technological advancement, invention and application of new minerals, automation and intelligence improvement, existing drilling technologies can be further improved and developed such as DWA, vertical drilling, under balance drilling etc.

\subsection{The Management Innovation Is the Key of Controlling Drilling Cost}

The scientific and effective management idea, or advanced management regulation is also a way of cost control [5]. Under the current situation, to establish full awareness, to arrange comprehensively in all production links and to coordinate with each other among all functional departments are contributed to finely cost control for full drilling process. So called fine cost control in full drilling process based on the scientific and effective management regulations is a kind of cost control system in which all drilling-related employees participate. The oil companies should seek for the ways to reduce cost in the full production and operation process in order to improve continually the enterprise competitiveness. In the drilling process that by the system was involved in, the cost incurred in every link need to be strictly controlled and audit. Why the money is spent? Which link the 
money is spent in? Who spent the money? Who the money is paid to? All the above questions need to be cleared meanwhile the corresponding cost control procedure need to be established so as to preclude unreasonable fee incurred in drilling cost. The objectivity of oilfield production needs to be considered adequately and controlling indexes of drilling cost are developed aimed to different reservoirs and blocks in which oil properties distributed [6] [7].

Except fine cost control management in full drilling process, management regulations of drilling system targeted at projects may be set up. The drilling cost projects implement special project, special fund and special purpose, and budget, accounting, assessment and evaluation are put into project management and control [8], especially pre-control management to high drilling cost is the highlight of development projects. In the process of project management, the benchmarking management system of exploitation wells is established, namely an exploitation well proposed in next five years is selected in the same reservoir and same layer series of development. The well is drilled aimed to realize the fundamental geologic tasks and deployment purposes, which can be standard well. The well designation and investment can be used as standard of proposed wells. The new wells designation and investment can't exceed the range of designation standard. Meanwhile, the drilling workload is divided into standard projects and non-standard projects. Whereby, standard projects can be properly implemented including drilling rig type, process, materials and facilities to ensure proper drilling footage. The non-standard projects can be implemented after the approval of relative departments in advance including rotary coring, unconventional technologies and materials etc.

\subsection{The System Innovation Plays the Most Important Role in Controlling Drilling Cost}

\subsubsection{Innovation in Marketization System}

The introduction of marketization system under the originalsystem by CNPC breaks the existing operating system. It will improve the drawbacks of original system and bring new develop opportunities in new period and environment. So does the marketization of drilling business. In the past, the drilling crew which belongs to the oil company was like 'The emperor's daughter' who never has to worry about her marriage, which means although in low oil price period, drilling crew that belongs to oil company still has lots of drilling activities. Some drilling crew even screens out the jobs. If the geological condition is complicated and the drilling job is difficult, the drilling crew would ask for a higher price which the oil company would not accept, given the truth that the drilling crew belongs to the oil company. Under the new marketization system, this problem would be completely solved. The decreased business opportunity and increased competition pressure will make the drilling crew change their arrogant attitude. The drilling crew would begin to seriously examine their ability to gradually adapt to market competition, and gain a foothold in the market by virtue of its own competitiveness.

\subsubsection{Innovation in Contracting System}

Influenced by the international oil price, the drilling industry is suffering in a hard time. Drilling service companies that have worked for oil companies for years are facing big challenges. It has been proved that international oil companies got good effect by changing the drilling contract mode. Therefore, in the drilling contracting process, an objective analysis and reasonable choice are needed. Some successful cases of foreign companies could be learned and the specific condition of China could be considered. Only in that way the right drilling contract method could be found and the best economic benefit could be achieved [9]. In the low oil price period, oil companies should sign long term contract with drilling service companies that have high qualification and good financial performance. On the other way, the oil companies should sign short term contract for single well with small companies that with good technology and long cooperation history. By the combination of long term contract and short term contract, the oil company should play the leading and coordinating role in order to go through the difficult time together with drilling service companies. Some international drilling contractors signed long term strategic cooperation agreement with big oil companies. For example, the Precision, an oil company in Canada, signed long term cooperation agreement with Schlumberger on the North America market [10] [11].

It should be noticed that the law and regulation that meet the need of marketization should be constructed under the consideration of current market environment before the introduction of market competition and new contracting system. The bidding and settlement processes of projects should be strictly checked in avoid of disorder and malicious competition [12]. The oil company should evaluate the lower limit of project cost, improve the analysis methodology of drilling cost, and combine the operating costing and standard costing into the cal- 
culating [13] in order to achieve the quantitative and delicacy management and build a scientific budget control system [14]. Some oil blocks should be chosen as the exemplary blocks of cost calculating. The blocks for contracting should be calculated after the cost calculation of exemplary blocks got good effect. The impact of different district, geological structure and well type on cost should be fully considered. The drilling service companies that ask for an unreasonable price or higher price than baseline should be warned or even forbidden for the competition. The drilling business marketization of oil companies could run in the healthy way [15].

\section{Results}

In the case of a substantial decline in the international oil price, international oil companies also adopted a number of measures of cost reduction and efficiency increase. Taking into account the reality of our country, the conditions and foundation of the oil companies, controlling the drilling cost is the major measure of costing reduction and improving the overall benefit at this stage. The measure of downsizing to improve benefit is still under no consideration.

Taking 5-year plan of some CNPC projects for example, the cumulative cash flow will increase $4.2 \%$ when the total investment is reduced by $1 \%$, and the cumulative cash flow will increase $3.8 \%$ when the total costs is reduced by $1 \%$. If the investment and costs are both reduced by $1 \%$, the project cumulative cash flow will increase $7.9 \%$. Therefore, controlling the investment and cost can greatly improve the economic benefits of the oil companies.

Since the oil and gas drilling investment in the composition of the oil and gas development investment accounted for a high proportion, oil companies' emphasis of cost reduction and benefit increase is how to control the increment of oil and gas drilling costs. The main pathway includes three aspects: the first is the technology innovation with improving drilling success rate and reducing drilling cycle as the target; the second is the drilling management innovation which carries out delicacy management of the whole process of drilling cost control and project system management; The third is the system innovation based on marketization and contract management. These practice and implementation of these pathways are effective strategies for oil companies to deal with low oil prices, control investment, reduce costs, and even improve the overall benefits under the new normal.

Taking a CNPC oilfield for example, it saved the investment for over 7 million RMB to apply the above methods and totally increase over 3000 tons oil with the total benefit about 2.6 million RMB.

\section{Conclusions}

1) Controlling drilling cost is the main method to improve the overall benefit of oil companies.

2) Quantitative analysis shows that the declination of investment and cost could increase the benefit dramatically in low oil price environment.

3) Innovation in technology, management and system is the only way to control drilling cost and improve benefit of oil companies.

\section{References}

[1] Xu, K., Hu, W.G. and Wang, S.H. (2015) Development Strategy of China’s Petroleum Enterprises under Background of Low Oil Price. Oil Forum, 34, 3-4.

[2] Lukawski, M.Z., Anderson, B.J., Augustine, C. and Capuano, L.E. (2014) Cost Analysis of Oil, Gas, and Geothermal Well Drilling. Journal of Petroleum Science and Engineering, 114, 1-14. http://dx.doi.org/10.1016/j.petrol.2014.03.012

[3] Bahari, A. and Seyed, A.B. (2009) Drilling Cost Optimization in a Hydrocarbon Field by Combination of Comparative and Mathematical Methods. Petroleum Science, 6, 451-463. http://dx.doi.org/10.1007/s12182-009-0069-x

[4] Power, M. (1995) The Effects of Technological Innovation on Hydrocarbon Discoveries. Resources Policy, 21, 263273. http://dx.doi.org/10.1016/0301-4207(96)85059-8

[5] Bernardo, M. (2014) Integration of Management Systems as an Innovation: A Proposal for a New Model. Journal of Cleaner Production, 82, 132-142. http://dx.doi.org/10.1016/j.jclepro.2014.06.089

[6] He, Z.M. (1999) Discussion about the Comprehensive Control of Drilling Cost. Natural Gas Technology and Economy, 6, 106-109.

[7] Niţă, C.G. and Ştefea, P. (2014) Cost Control for Business Sustainability. Procedia—Social and Behavioral Sciences, 124, 307-311. http://dx.doi.org/10.1016/j.sbspro.2014.02.490 
[8] Ma, X.Y. (2013) The Drilling Cost Management and Control Based on Project Team Management. Friends of Accounting, 3, 37-38.

[9] Yang, C.B. and Fan, N.Q. (2013) Discussion about the Types of Drilling Contract in Sudan Petroleum Market. Chemical Enterprise Management, 24, 28-29.

[10] Yang, J.H. and Guo, X.X. (2015) The International Drilling Contract Market in the Low Oil Price Environment. International Petroleum Economics, 23, 25-30.

[11] Jiang, D.H. (2012) On Effective Control of Drilling Cost through Total Factor Cost Management of Single Well Contract. Journal of Jianghan Petroleum University of Staff and Workers, 25, 40-45.

[12] Shiravi, A. and Majd, F.A. (2015) Foreign Investment in Iran’s Upstream Oil and Gas Operations: A Legal Perspective. The Journal of World Energy Law \& Business, 8, 269-287. http://dx.doi.org/10.1093/jwelb/jwv005

[13] Jin, S.Z. (2013) Discussion on Several Issues of Drilling Cost Control in the Oilfield Enterprise. Economic Research Guide, 10, 114-115.

[14] Yin, D.R. (2008) Fine Management of Drilling Cost. China Petroleum Enterprise, 11, 88-89.

[15] Si, G. and Wei, L.H. (2009) The Main Influencing Factors on the Drilling Cost and the Corresponding Controlling Measures. Natural Gas Industry, 29, 106-109. 